\title{
Focus on acetabular fractures
}

\author{
Pol M. Rommens ${ }^{1}$. Johannes D. Bastian ${ }^{2}$
}

(c) The Author(s) 2021

Displaced acetabular fractures have always been a major challenge for trauma surgeons. Conservative management includes immobilization in bed during several weeks and regularly results in a moderate functional outcome. For surgical treatment various surgical approaches are established [1]. A skilled selection of the appropriate surgical approach is essential as large incisions used to reach the innominate bone and acetabulum can cause severe surgical complications. Open reduction and internal fixation (ORIF) is the method of choice in patients below the age of 60 . After adequate surgery, conversion to a total hip arthroplasty following posttraumatic osteoarthritis can be avoided in up to $80 \%$ of patients [2]. In patients above the age of 60 , there is an ongoing discussion on the best method of treatment. ORIF is only accepted, when the joint is good reconstructible and in absence of preexisting osteoarthritis [3, 4]. In other cases, acute total hip arthroplasty is the method of choice with or without ORIF (the "Combined Hip Procedure").

There is an ongoing research on how to predict outcome of acetabular fracture surgery. Preoperative planning through analysis of CT data, 3D printing and the development of patient-specific implants are new developments, which may help the trauma surgeon in performing a successful and less invasive surgery.

In this focus on, different authors highlight problem-oriented solutions for safe surgery of acetabular fractures. In a retrospective comparative study, Ansari et al. [5] investigated the role of preoperative $3 \mathrm{D}$ printing of the fractured innominate bone for the performance of the surgeon. There was a significant decrease in the operative time, amount of intraoperative blood loss and number of intraoperative fluoroscopy

Pol M. Rommens

prommens@uni-mainz.de

1 Department of Orthopaedics and Traumatology, University Medical Center of Johannes Gutenberg-University Mainz, Mainz, Germany

2 Department of Orthopaedic Surgery and Traumatology, Inselspital, Bern University Hospital, University of Bern, Bern, Switzerland images in the 3D printing group. This investigation underlines the importance of 3D imaging for better understanding of the acetabular fracture anatomy. Tomaževič et al. [6] performed a comparative experimental study with 3D printed patient-specific implants and drill guides for reduction and fixation of an anterior column and posterior hemitransverse fracture. In fracture models, which were stabilized with implant-specific implants, the quality of reduction was significantly better. Patient-specific implants may facilitate retaining an accurate reduction and fixation of displaced acetabular fractures. Osterhoff et al. [7] compared the biomechanical behavior of antegrade and retrograde screw fixation of the anterior column in acetabular fractures. They did not find significant differences in construct survival, mode of failure and load to failure. These are interesting results for the surgeon, as she/he can choose the one or other screw direction depending on the surgical exposure. Fairhurst et al. [8] correlated the Estimation of Physiologic Ability and Surgical Stress (E-PASS) score with postoperative complications in acetabular fracture management. They found a significant correlation between complication rates and either the preoperative risk score (PRS) or the comprehensive risk score (CRS). They conclude that there is an important role for perioperative care in prevention, early recognition and treatment of perioperative complications. This is especially true for the older patient with an acetabular fracture and should motivate to setup an orthogeriatrie care. Bastian et al. [9] looked at the risk of intra-articular screw placement in patients with increased acetabular depth in 112 patients. There was a virtual possibility to place an infra-acetabular screw in all patients. Nevertheless, an increasing depth of the acetabulum correlated with a decrease in distance between the femoral head and the screw. Ruling out of intra-articular screw placement remains very important in every surgery.

This focus on presents original clinical and experimental research, which is connected with the management of acetabular fractures. The reader discovers the value of 3D printing for better preoperative planning and of thorough preoperative estimation of the perioperative risks. Moreover, she/he learns about the stability of antegrade and retrograde 
fixation of the anterior column and of the risk of joint penetration in infra-acetabular screw placement. These new aspects may help the acetabular trauma surgeon for optimal preoperative planning and performing an uneventful and high-quality surgery. We wish you very interesting readings.

Prof. Dr. Dr. h. c. Pol M. Rommens

Guest-editor

Prof. Dr. Johannes D. Bastian

Guest-editor

Funding Open Access funding enabled and organized by ProjektDEAL.

\section{Declarations}

\section{Conflict of interest None.}

Open Access This article is licensed under a Creative Commons Attribution 4.0 International License, which permits use, sharing, adaptation, distribution and reproduction in any medium or format, as long as you give appropriate credit to the original author(s) and the source, provide a link to the Creative Commons licence, and indicate if changes were made. The images or other third party material in this article are included in the article's Creative Commons licence, unless indicated otherwise in a credit line to the material. If material is not included in the article's Creative Commons licence and your intended use is not permitted by statutory regulation or exceeds the permitted use, you will need to obtain permission directly from the copyright holder. To view a copy of this licence, visit http://creativecommons.org/licenses/by/4.0/.

\section{References}

1. Cheng EY, Bastian JD. Selecting surgical approaches for treatment of acetabular fractures. JBJS Essent Surg Tech. 2019;9(1): e4. https://doi.org/10.2106/JBJS.ST.18.00102 (PMID: 31086722; PMCID: PMC6485768).

2. Tannast M, Najibi S, Matta JM. Two to twenty-year survivorship of the hip in 810 patients with operatively treated acetabular fractures. J Bone Jt Surg Am. 2012;94(17):1559-67. https://doi.org/ 10.2106/JBJS.K.00444 (PMID: 22992846).

3. Rommens PM, Schwab R, Handrich K, Arand C, Wagner D, Hofmann A. Open reduction and internal fixation of acetabular fractures in patients of old age. Int Orthop. 2020;44(10):2123-30. https://doi.org/10.1007/s00264-020-04672-0 (Epub 2020 Jul 30. PMID: 32734382; PMCID: PMC7584535).

4. Rommens PM, Herteleer M, Handrich K, Boudissa M, Wagner D, Hopf JC. Medial buttressing of the quadrilateral surface in acetabular and periprosthetic acetabular fractures. PLoS ONE. 2020;15(12): e0243592. https://doi.org/10.1371/journal.pone. 0243592 (PMID: 3284841; PMCID: PMC7721143).

5. Ansari S, Barik S, Singh SK, Sarkar B, Goyal T, Kalia RB. Role of 3D printing in the management of complex acetabular fractures: a comparative study. Eur J Trauma Emerg Surg. 2020. https://doi. org/10.1007/s00068-020-01485-z (Epub ahead of print. PMID: 32918149).

6. Tomaževič M, Kristan A, Kamath AF, Cimerman M. 3D printing of implants for patient-specific acetabular fracture fixation: an experimental study. Eur J Trauma Emerg Surg. 2019. https://doi. org/10.1007/s00068-019-01241-y (Epub ahead of print. PMID: 31641786).

7. Osterhoff G, Wulsten D, Babu S, Heyland M, Pari C. Antegrade versus retrograde screw fixation of anterior column acetabular fractures: a biomechanical in vitro study. Eur J Trauma Emerg Surg. 2019. https://doi.org/10.1007/s00068-019-01255-6 (Epub ahead of print. PMID: 31664465 ).

8. Fairhurst PG, Tsinas D, Shokiche CC, Keel MJB, Siebenrock KA, Bastian JD. The use of the E-PASS scoring system in determining complication development in patients with isolated acetabular fractures. Eur J Trauma Emerg Surg. 2020. https://doi.org/ 10.1007/s00068-020-01395-0 (Epub ahead of print. PMID: 32447403).

9. Bastian JD, Näf DR, Cullmann JL, Keel MJ, Giannoudis PV. Does increased acetabular depth affect safe infra-acetabular screw placement in acetabular fracture fixation? Eur J Trauma Emerg Surg. 2020. https://doi.org/10.1007/s00068-020-01455-5 (Epub ahead of print. PMID: 32728900). 